\title{
THE BIPOLARITY OF PERSONAL CONSTRUCTS
}

\author{
RAINER RIEMANN \\ Universität Bielefeld, Abt. Psychologie, Postfach 8640, \\ D-4800 Bielefeld, Federal Republic of Germany
}

\begin{abstract}
An important aspect of Kelly's (1955) personal construct theory is the postulate that all human thinking is dichotomous in nature. Empirical research and theoretical arguments, hourter, question the validity of this postulate. We used a repertory grid test to study personal constructs. Conditions were created to encourage the bipolar use of personal constructs. Furthemore, half of the subjects were encouraged to list more than two poles for a construct. Results shourd that bipolarity is an important but not an essential aspect of personal constructs. A reconceptualization of contrast relations between construct poles is presented that encompasses more than two contrasting concepts and is in line with the concepts of taxonomy and semantic contrast in psycholinguistic and cognitive psychological research.
\end{abstract}

Since Kelly (1955) first put forward The Psychology of Personal Constructs, this theory has gained a prominent position in the scientific study of the person. An important part of the theory may be characterized as a theory of knowledge centering around the question of how people acquire knowledge about themselves and other events around them. Kelly (1955) proposed that people develop idiosyncratic concepts (personal constructs) to organize stimuli of the physical, social, or "inner" world into meaningful patterns. These personal constructs are (more or less) integrated into hierarchically organized construct systems.

Kelly ascribed a dichotomous quality to all human thinking. In contrast to the notion of a concept, every single construct is regarded as a dichotomous abstraction. The formation of a construct is based on a process in which a person notes that some events are similar among themselves with respect to certain features and differ from other events with respect to the same features. However, this

This article is based on part of a doctoral dissertation at the University of Bielefeld (see Bonarius (1988) for a review).

The author would like to thank Alois Angleitner, Han Bonarius, and Peter Borkenau for helpful comments on earlier versions of this article, and Jonathan Harrow for his assistance in preparing the manuscript. 
classification of events, which is captured by the dichotomy postulate, does not fit very well with our commonsense experience. We use concepts not only for an absolute categorization but also for ordering events along a specified dimension. Usually we do not decide whether a person is either extraverted or introverted, but compare persons with one another according to their degree of extraversion or introversion. This ordering is denoted here as the bipolar use of a construct. Kelly (1955) proposed a number of combinations of dichotomous constructs (including hierarchical scales, additive scales, abstracted scales, approximation scales, and accumulation scales) to transform "black and white" distinctions into shades of gray (for a critique of the logic behind these scales, see Wijdeveld, 1980).

In line with Kelly's reasoning we can easily realize that in everyday language the communication of contrasting terms is very useful for clarifying the meaning of an assertion. For example, the meaning of man is different when contrasted with woman than with boy. Likewise in psychological research, bipolar concepts play a prominent role, especially in personality research (e.g., Buss \& Craik, 1983; Cattell, 1943; Goldberg \& Kilkowski, 1985; Norman, 1963; Wiggins, 1979). However, neither the importance of bipolar terms in everyday conversations nor the frequent use of bipolar concepts in psychological research and theorizing are direct evidence in favor of Kelly's dichotomy postulate. In contrast to the widespread acceptance of the dichotomy postulate among proponents of personal construct theory, direct empirical research and theoretical arguments question its validity.

Some early studies (see Bonarius, 1965, for a review) were directed at the question of whether personal constructs are used in a bipolar or even dichotomous way. Most of these studies yielded very indirect evidence in favor of the bipolarity postulate. For example, Resnick and Landfield (1961) were able to demonstrate that the opposing poles of personal constructs share common and partially opposing facets of meaning. The most direct tests, however, were carried out using variants of the repertory grid technique.

Mair (1967) presented trait adjectives to his subjects and asked them to specify the opposite pole. For each of the adjectives and each of the contrasts, the subjects had to select 10 out of 20 names of people well known to them ("split-half grid"; Bannister, 1960). Mair reported a dichotomous or near dichotomous use for only $22 \%$ of the constructs. For $84 \%$ of the constructs a substantial negative relationship $(p<.12$; matching score $0-6)$ was observed.

A similar study was reported by Epting, Suchman, and Nickeson 
(1971). They compared two methods of eliciting constructs in bipolar form: the difference method and the opposite method. In both methods the likeness end of a construct is the word or short phrase given by the subject to describe the similarity of two (out of three) personal acquaintances (elements). Using the difference method, the contrast was given by the subject as an answer to the question: "In what respect does the third element differ from two others?" In the opposite method, the subjects were asked what they considered to be the opposite of the characteristic listed for the likeness end. Epting et al. observed significantly less overlap between construct poles for the opposite method. Averaged over both methods, the results were close to those reported by Mair. For $24 \%$ a perfect or near perfect dichotomy was observed; $64 \%$ (73\% for the opposite method) of constructs showed a substantial $(p<.05$; matching score $0-6)$ negative relationship.

These results raise doubts that the relationship between construct poles is seized adequately by Kelly's dichotomy corollary. Although negative relationships can be observed for the majority of constructs, the percentage of perfect bipolar constructs is quite low. It should be noted, however, that a number of factors may work to lower the observed bipolarity. The sortings of the elements are severely restricted by the split-half procedure. Studies in which subjects were allowed to assign as many elements to either pole as they liked demonstrated a remarkable preference for describing elements with the likeness pole (Adams-Webber, 1979). The forced choice procedure applied in the previously mentioned studies may lead to a random selection of elements that are not subsumed under the construct pole although better described by this pole, and a random selection of additional elements described by the contrast pole although they would be more appropriately subsumed under the construct pole. In addition, those personal acquaintances, who are neither subsumed under the likeness pole nor under the contrast pole of the construct, lower the obtained measure of bipolarity. Furthermore, it seems plausible to assume that certain constructs are meaningful only within certain contexts (e.g., social situations). The limited space for writing down construct labels makes it impossible to specify any context. Forgetting or changing the context when completing the ratings may substantially alter the meaning of a construct label, especially when the opposite pole is not presented simultaneously (Mair, 1967). As all these factors result in an underestimation of the bipolarity, the reported studies may not be interpreted as an unequivocal rejection of Kelly's bipolarity postulate. In addition to these empirical findings, Bonarius (1984), Bona- 
rius, Angleitner, and John (1983), and Wijdeveld (1980) list a number of theoretical arguments questioning the appropriateness and usefulness of the bipolarity postulate.

With the dichotomy corollary, Kelly wanted to emphasize the distinction between contrasting elements (masculinity vs. femininity) and irrelevant elements (masculinity vs. time of day). In his critical analysis, Wijdeveld (1980) points to the parallel between Kelly's concept of the "range of convenience" and Boole's (1854/1952) "universe of discourse." We can make a meaningful assertion about an entity only if the subject of the discourse (universe of discourse) has been (implicitly) defined. This universe of discourse does not encompass all beings or objects to which a name or description is applicable, but only those which exist in the supposed universe of discourse (Boole, 1854/1952). Within the universe of discourse, all elements not subsumed by the (monopolar) construct are, by definition, in contrast with this construct without being similar among themselves (Bonarius, 1984). On the basis of these arguments and the empirical results reported above, Bonarius (1984) argued that the dichotomy corollary (Kelly, 1955) should be eliminated from the basic theory of personal constructs or be substituted by a limitation corollary: "A person's construction system is composed of a limited number of (monopolar or singular) constructs" (Bonarius, 1984, pp. 199-200). This monopolar definition would also make the ordering of elements with respect to this construct more transparent.

However, Bonarius's limitation corollary gives little weight to contrast relations between construct poles. In agreement with the argument that within a fixed universe of discourse all elements not subsumed by a monopolar construct must not necessarily be similar among themselves, it might be argued that by the use of a construct the universe of discourse (range of convenience) is partitioned into two or more than two classes of entities. In this case, direct contrast relations (Kay, 1971) may exist between more than two concepts.

The present study serves two goals: On the one hand, the effect of the major previously mentioned factors on the bipolarity of personal constructs is studied. The procedure developed by Mair (1967) and Epting et al. (1971) is partially replicated. The experimental conditions and the methods of data analysis are selected specially to minimize factors that lower the degree of bipolarity. On the other hand, more complex contrast relations involving more than two poles are studied. Therefore half of the subjects are given the opportunity to generate more than two poles of a construct to study the readiness with which this option is taken, and to examine the structure of these multiple construct poles. 


\section{METHOD}

\section{Overview}

Subjects were assigned to one of four experimental groups. Two independent variables were completely crossed: (a) elicitation of one versus multiple contrast poles, and (b) specification of context versus no specification of context. Subjects in Groups B and D were encouraged to list more than one contrasting description for a construct whenever it seemed meaningful to them. Subjects in Groups $A$ and $C$ were allowed to list only two poles of a construct. Groups $C$ and $D$ were instructed to specify the context they had in mind when generating the construct. Groups A and B did not specify the context. Constructs were generated using the procedure suggested by Kelly (1955) with some modifications. The construct poles were presented to the subjects in random order during a second session. Ratings for 22 personal acquaintances were gathered on each pole separately.

\section{Subjects}

Undergraduate psychology students (15 female and 9 male), who were ages 19 to 24 years old, volunteered for the study. They were randomly assigned to one of the four groups. Two subjects assigned to Group B had to be discarded: One subject did not participate in the second session and a second failed to follow instructions, leaving a final sample of 22 subjects.

\section{Procedure}

Subjects participated in two experimental sessions. The mean time between the sessions was 8 days. Subjects completed the tasks in small groups of two to three participants each.

\section{First Session}

Subjects were given a booklet with instructions and 22 small cards on which the names of personal acquaintances had to be written according to the following role title list: self, mother, father, brother/sister, spouse, opposite-sex friend, two disliked persons, pitied person, well-known liked lecturer, disliked lecturer, six fel- 
low students (known for at least three months), and four "nonuniversity" acquaintances (known for at least three months). After the elicitation of the elements, a second pile of cards was given to the subjects on which they could write the construct poles. Fifteen triads of the listed persons had been specified in the instructions. These triads of elements were selected randomly on the condition that every element was approximately equally represented in the triads. Subjects were asked to write in what important respect were two of the three selected persons alike and different from the third (contrast method). The likeness end label and the contrast end label were written on different cards each.

\section{Specification of the Context}

Subjects in Groups C and D were given another pile of cards for specifying the context in which the construct was used. After the elicitation of each single construct, they were instructed: "After you have listed the two characteristics, please specify the aspect that was on your mind when you differentiated between the people. For example, suppose you described two people as old and the third as young. In doing this you might have been referring to the chronological age of the people, to their behavior toward other people, or to their attitudes. Please describe as detailed and exactly as possible that aspect that was on your mind."

\section{Elicitation of Further Contrasts}

After the elicitation of two construct poles and the specifications of the context (Group D), the subjects in Groups B and D were encouraged to list more contrasting concepts. To make this procedure plausible, the following instruction was presented: "After you have described three people with reference to one aspect, imagine you had to describe all other persons you listed before according to the same aspect. Do you think that two categories are sufficient for this description? Perhaps you would prefer to make more than two distinctions. Specify these distinctions by adding one or more cards to the other two." A sufficient number of cards was provided to make additional distinctions.

All subjects completed the procedure in a fixed sequence: First two poles were elicited (all groups), thereafter subjects in Groups $C$ and $D$ specified the context, and finally further contrasts were elicited (Groups B and D). 


\section{Second Session}

In the second session, ratings of all elements on every single construct pole were collected. A separate booklet was prepared for every subject, each containing at least 3 pages. A grid ( 22 columns, 10 rows) was drawn on each page. On the top of the grid the names (or initials) of all elements were listed. All poles of the constructs were presented on cards to the subjects in a random order. Care was taken that different poles of the same construct were rated on different pages whenever possible. Every element was rated on every construct pole separately. A 4-point scale was provided for these ratings, ranging from "this description does not apply to the person" ( -0$)$ to "... does apply very well" (-3). Subjects in Groups $C$ and $D$ were presented with the description of the context accompanying the respective constructs' poles. All necessary identifications had been removed so that the subjects were not able to identify which cards represented different poles of the same construct.

\section{Data Analysis}

To calculate the degree to which ratings on personal constructs are bipolar, the monotone relationship between the two poles over the 22 ratings was calculated using the $\mu_{2}$-coefficient (cf. Maimon, 1978):

$$
\mu_{2}=\frac{\sum_{j=1}^{22} \sum_{i=1}^{22}\left(x_{i}-x_{j}\right)\left(y_{i}-y_{j}\right)}{\sum_{j=1}^{22} \sum_{i=1}^{22}\left|\left(x_{i}-x_{j}\right)\left(y_{i}-y_{j}\right)\right|}
$$

in which $x_{i}\left(x_{j}\right)$ gives the rating of element $i(j)$ on the likeness pole and $y_{i}\left(y_{j}\right)$ the rating of element $i(j)$ on the contrast pole. This coefficient reaches its minimum value $(-1.0)$ if every element can be located on a dimension so that the relative position on this dimension perfectly corresponds to the rank order of ratings on both poles, and higher ratings on one pole are paired with lower ratings on the other. It should be noted that the absolute value of the $\mu_{2}$ coefficient is always greater or equal to the absolute value of the product-moment correlation. Figure 1 gives two examples of perfect monotone regressions on the basis of different ratings. Suppose the 
first example in Figure 1 is based on the construct pole "extraverted" and the contrast pole "introverted." There are six elements that were rated as either introverted or extraverted, but differing in their degree of the introversion/extraversion. These ratings correspond perfectly to the definition of bipolarity given previously.

In order to maximize the degree of observed bipolarity for each pair of construct poles, two coefficients were computed: one including elements that were judged as not being subsumable under either pole of the construct, another excluding these ratings from analysis. If a coefficient turned negative when the "not applicable" ratings were deleted from computation or the absolute value of a negative coefficient was increased, then these coefficients were subjected to further analysis.

To estimate the statistical significance of the results, a Monte Carlo study was carried out. One thousand pairs of "ratings" were produced using a random number generator. For each comparison 22 digits between 0 and 3 were generated twice. An even distribution was assumed which is quite close to the actual ratings obtained in the study (likeness end rating $0=26.7 \%, 1-25.3 \%, 2-26.3 \%$, $3=21.8 \%$; contrast pole rating $0=29.1 \%, 1-26.7 \%, 2-24.8 \%$, $3=19.3 \%)$. Between these random "ratings" $\mu_{2}$-coefficients were
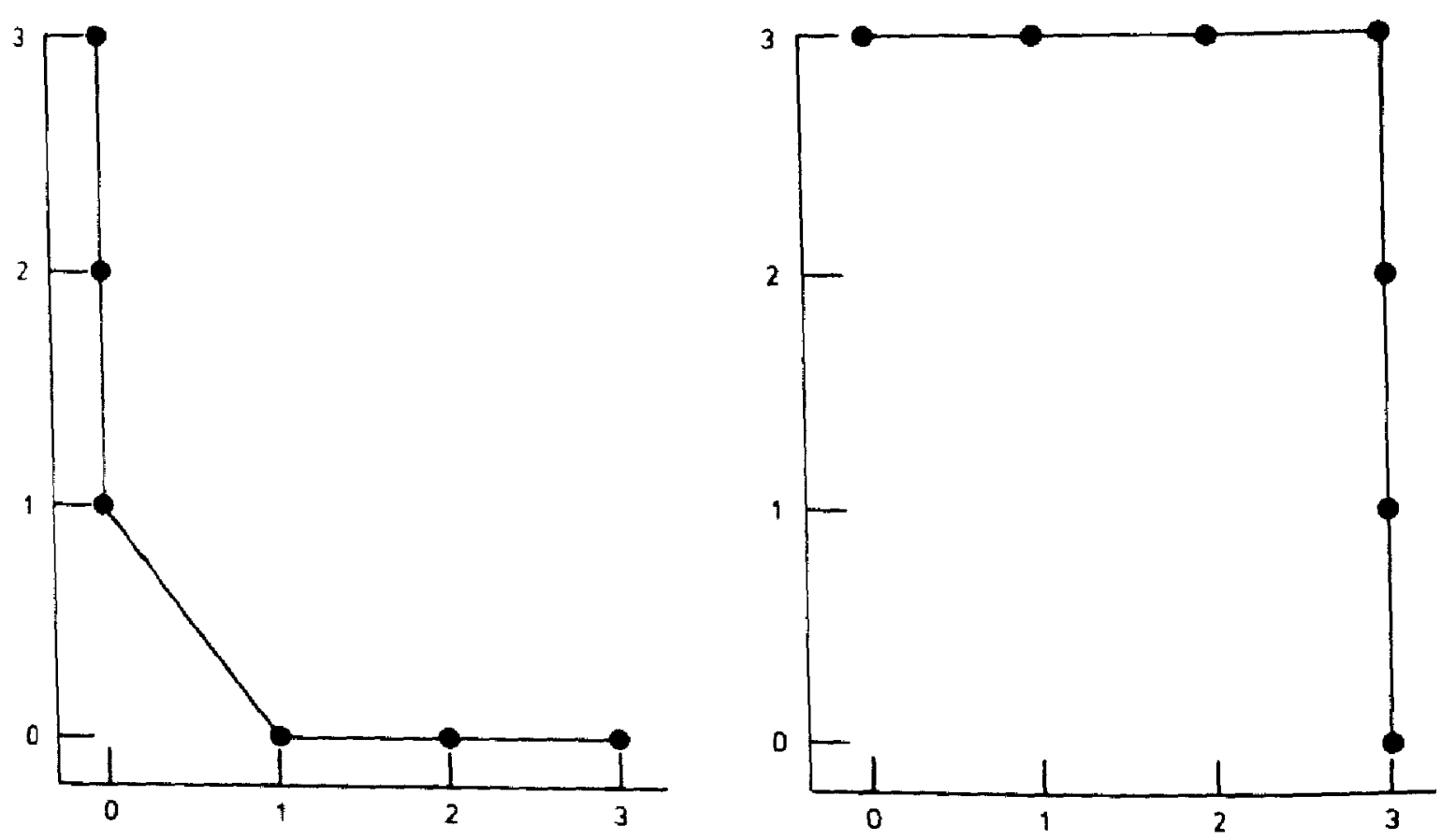

FIGURE 1 Hypothetical ratings showing perfect monotone relationships. Ratings (03) referring to one pole of the construct are displayed on the $x$ axis and $y$ axis, respectively. 


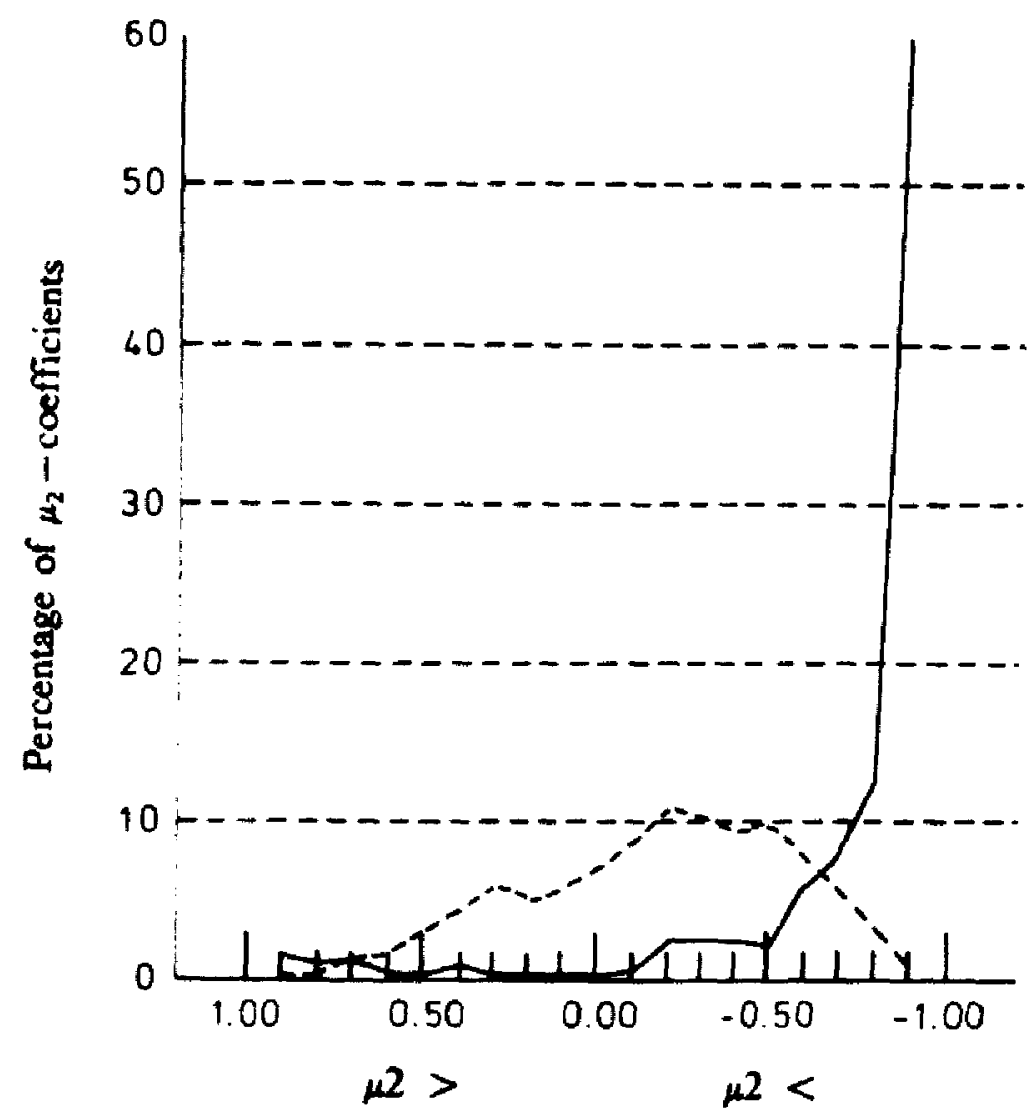

FIGURE 2 Distribution of $\mu_{2}$-coefficients calculated between construct poles. The solid line represents the observed distribution (averaged over all groups), the broken line the random distribution.

computed using the same procedure as described. The resulting distribution is given in Figure 2.

\section{RESULTS}

\section{Bipolarity of Construct Poles Elicited in the Triadic Comparison Procedure}

As can be seen from the distribution of the $\mu_{2}$-coefficients displayed in Figure 2, the vast majority of construct poles showed a negative relationship. Averaged over all subjects, $93.9 \%$ of the coefficients were negative and $58.1 \%$ were less than $\mu_{2}=-.90$. The latter can be regarded as indicating perfect and near perfect negative relationships ( $p<.008$ for random numbers). The distribution showed a slight increase for $\mu_{2}$-coefficients higher than .70 .

To test the influence of specifying the context, the mean number of perfect negative relationships $\left(\mu_{2}--1.0\right)$ was computed for each 
group. A comparison of the means showed that, contrary to the hypothesis, the mean of the combined Groups $A(M-2.83, s-2.14)$ and $B(M=5.25, s=3.50)$ was higher than the mean for the combined Groups $C(M=4.00, s-3.52)$ and $D(M-3.50, s-1.05)$, that specified the context. This difference was statistically nonsignificant. A similar pattern of results could be observed for the means of the $\mu_{2}$-coefficients. These amounted to $M=-.74(s-.10)$ for Group A; $M=-.81(s-.08)$ for Group B; $M=-.66(s-.23)$ for Group $C$; and $M=-.78(s-.14)$ for Group $D$. The mean of the "context" groups was higher than that of the "noncontext" groups, indicating less bipolarity. A comparison of the two groups (B and D) that were given the opportunity to list more than two poles revealed that these groups combined yielded a higher mean of $\mu_{2}$-coefficients than the groups that specified exactly two poles. However, this difference did not reach the conventional level of statistical significance $[t(20)=$ 1.556 , n.s.].

An inspection of the construct poles gave no clear hint in what respect bipolar constructs psychologically differ from the others. Among both bipolar and nonbipolar constructs personality descriptive terms or short phrases were very frequent. Construct poles that were positively related often represented similar and not semantically opposed concepts (e.g., easily makes a compromise/less willing to make a compromise; both might be contrasted to: does not make a compromise).

\section{Multiple Contrasts}

Nine out of the 10 subjects in Groups B and D listed additional contrasts for some constructs. One subject reported that for him two poles had been sufficient for each comparison. The remaining subjects generated on average $9.33(s-2.29)$ additional contrasts without reporting any difficulties. The distribution of the number of additional contrasts was as follows: One additional pole was listed in $60.7 \%$ of the "multipolar" constructs, two in $25.0 \%$, and three and four in $7.7 \%$ each. To examine the structure and especially the dimensionality of each multipolar construct, Euclidian distances were computed between any pair of the elements $\left(D_{j k}\right)$ according to the following formula:

$$
D_{j k}=\left[\sum_{i=1}^{n}\left(x_{i j}-x_{i k}\right)^{2}\right]^{0.5}
$$


in which $n$ gives the number of construct poles, $x_{i j}$ denotes the rating of element $j$ in reference to construct pole $i$, and $x_{i k}$ the respective rating for element $k$. These distances were computed over the maximally six poles and then analyzed using a nonmetric multidimensional scaling procedure (MINISSA). Different structures of the element space showed up in the scaling solutions. These were easily interpretable since the number of poles was small. A sample solution is presented in Figure 3.

On the basis of these solutions and the computation of $\mu_{2}$ coefficients between all pairs of construct poles, the multiple constructs could easily be assigned to one of the following categories: (a) 40 constructs $(47.6 \%)$ were unidimensional and the additional was used in a very similar way to the likeness or contrast pole; (b) 1 construct $(1.2 \%)$ was a unidimensional construct in which likeness and construct pole were positively related, and the additional concept was used as a contrast; (c) 28 constructs (33.3\%) were higher dimensional constructs in which likeness and contrast pole were located in one dimension and the additional contrasts in independent dimensions; (d) 11 constructs $(13.1 \%)$ were higher dimensional constructs in which an additional contrast was located in one dimension with either likeness or contrast pole, and likeness and contrast pole were not located in one dimension; (e) the poles of 4 constructs $(4.8 \%)$ were each located in independent dimensions. Thus, nearly half of these constructs may be regarded as approximately unidimensional. In these cases the additional contrasts (with one exception) were used in a similar way to either the likeness or contrast poles. The labels used for these additional contrasts usually represented an intermediate term between the poles elicited in the triadic comparison (e.g., gregarious vs. aloof vs. has to be motivated). One third of the multiple constructs showed a multidimensional structure in which the additional contrasts were represented in additional dimensions (e.g., even-tempered vs. hectic; additional contrast: active).

\section{DISCUSSION}

The results of this study point out that bipolarity is an important aspect of personal constructs, but by no means are personal constructs always used in a bipolar way. Approximately half of the constructs elicited via the triadic comparison procedure are used in a bipolar way for describing acquaintances in a repertory grid test. The present results suggest that the degree of personal constructs' bipolarity has been underestimated by Mair (1967) and Epting et al. 


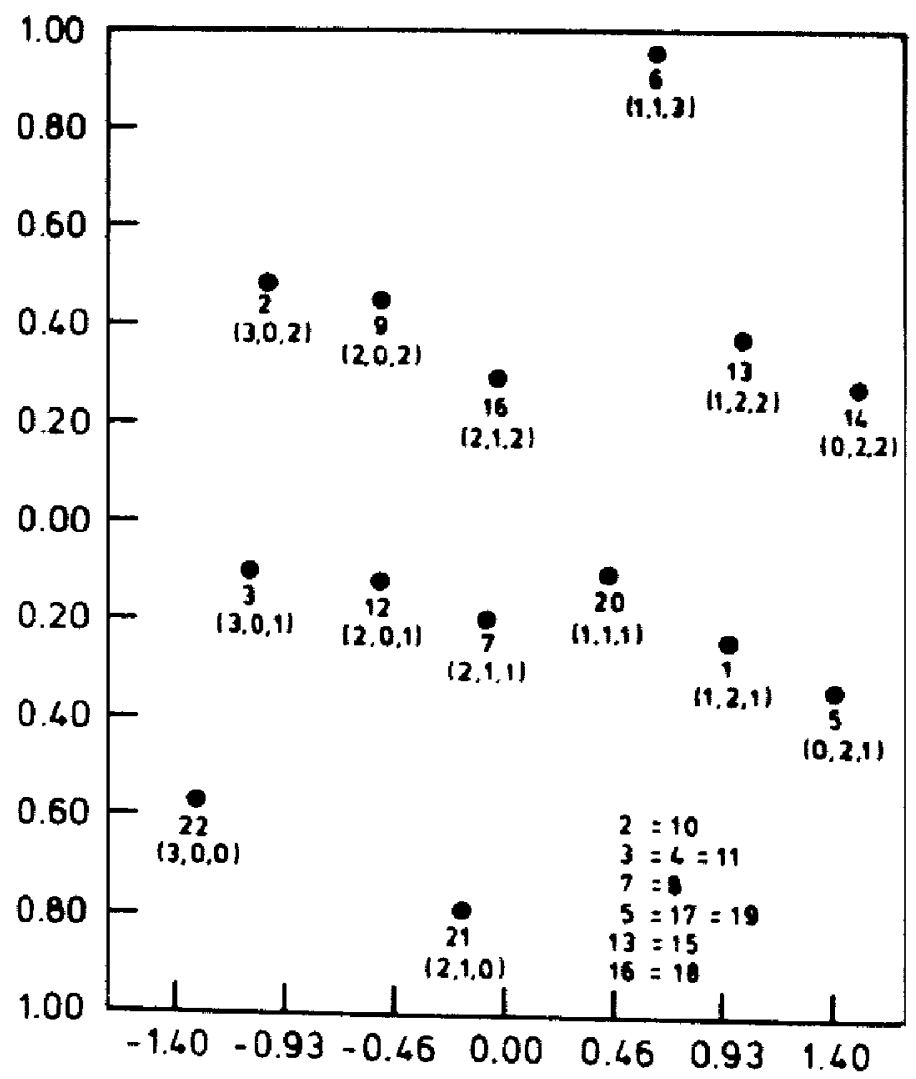

FIGURE 3 A sample nonmetric multidimensional scaling solution. Likeness pole: established; constrast: seeking; additional pole: presents himself as stable but inwardly he is uncertain. The numbers in parentheses show the rating of the respective element on the likeness pole, the contrast pole, and the additional pole.

(1971). In both studies, a very similar percentage of bipolar or near bipolar constructs ( $22 \%$ and $24 \%$, respectively) was reported. The higher degree of observed bipolarity is largely due to a more appropriate calculation of the relation between construct poles.

The specification of the context and the elicitation of additional contrasts have no substantial effect on these results. Contrary to the hypotheses, the bipolarity was more pronounced for the groups that did not specify a context. It should be noted, however, that subjects in all experimental conditions were provided with much more space for specifying the construct poles than in the usual procedure. In view of these data it seems less plausible to assume (cf. Mair, 1967) that constructs are not used in a bipolar way because they summarize actions, intentions, or potentials of a person, rather than the total person.

Additional evidence from the analysis of multipolar constructs 
points out that the structure of construct poles is not captured adequately by Kelly's dichotomy postulate. Subjects readily list several contrasts for a construct pole. For approximately half of these multipolar constructs, a unidimensional representation of the elements' ordering seems inappropriate. Thus, the assumption that contrast relations may exist between more than two construct poles seems to be more appropriate. To illustrate this point, a hypothetical example is given in Figure 4. This more differentiated structure of construct poles leans on Wiggins's (1979) circumplex model.

Suppose a person uses the adjectives given in Figure 4 for describing the social behavior of other persons (social behavior was frequently mentioned as context in this study). The spatial location of the adjectives corresponds to the structure of their meaning. The smaller the spatial distance between two adjectives, the more similar they are in meaning. The capital letters might represent the position of personal acquaintances in reference to the adjectives. If the hypothetical person has to compare $\mathrm{A}, \mathrm{B}$, and $\mathrm{Q}$, the construct warm versus cold might be elicited. If, however, the triads A, C, and F or A, C, and $K$ are selected, the person might list constructs like warm versus unassuming or warm versus submissive. Although the latter construct poles do not consist of antonyms, they may be seen as meaningful contrasts: For example, $A$ and $C$ show warm social behavior, whereas $\mathrm{K}$ shows submissive behavior in social situations. If the other personal acquaintances are rated in reference to these construct poles, cold

Werm

A

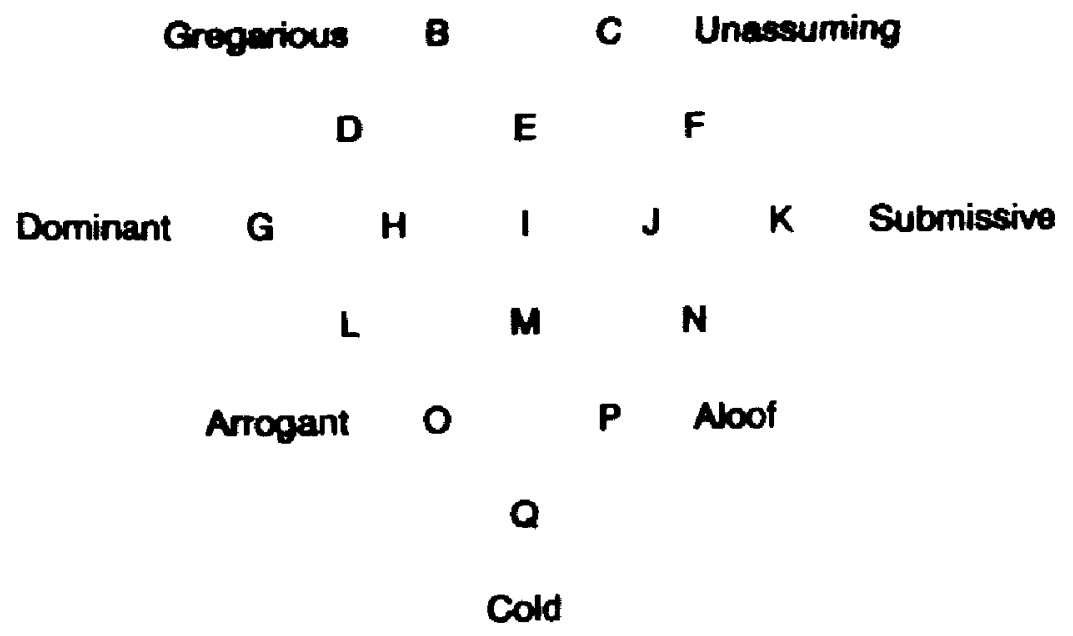

FIGURE 4 Hypothetical example for the structure of a multipolar construct. 
versus warm would be used in a perfectly bipolar way; between warm and submissive an orthogonal relationship would be observed, and finally warm and unassuming would be positively related.

This extended conceptualization of the relationship between construct poles is in line with the data in that it does not imply bipolarity between contrasting construct poles, although obviously the instructions foster the elicitation of negatively related construct poles. The finding reported by Epting et al. (1971)-that construct poles elicited by the opposite method are more negatively related than construct poles elicited via the difference method-fits nicely into the present conceptualization. The opposite method leads to the elicitation of antonymous poles in those cases in which more than two poles are in contrast relation, as the attributed characteristics of the third person do not need to be considered.

The present results do not challenge Kelly's basic observation that a construct denotes both similarity and contrast. However, they present strong qualifications to Kelly's dichotomy corollary. A parsimonious way to incorporate the empirical evidence from the studies by Mair (1967), Epting et al. (1971), and the present study, as well as the logical analyses by Wijdeveld (1980) and Bonarius (1984) in the basic theory of personal constructs, is to regard personal constructs as monopolar abstractions (see Bonarius's limitation corollary above). Contrast relations between two or more constructs can be conceptualized as an aspect of the organization of personal constructs. Thus, the organization corollary has to be extended to capture ordinal (hierarchical) relationships between constructs at different levels of abstraction and direct contrast relationships between constructs at the same level of abstraction: Each person characteristically evolves, for his or her convenience in anticipating events, a construct system embracing ordinal and contrast relationships between constructs.

The proposed reconceptualization bridges the gap between personal construct theory and modern approaches in psycholinguistics and cognitive psychology (e.g., Rosch et al., 1976, on taxonomies of natural objects; Cantor \& Mischel, 1979, on taxonomies of persons) because the reformulation of the organization postulate is in line with Kay's (1971) formal definition of the concepts of taxonomy and semantic contrast. Our understanding of the organization and internal structure of personal constructs especially may gain a lot from the incorporation of the respective approaches. Furthermore, Ten Kate (1981) has shown that the study of hierarchically organized construct systems is severely limited by an adherence to the dichotomy postulate. The extension of the organization corollary forms the theoretical basis for the study of broader taxonomies of personal constructs. 
In the discussion concerning the dichotomy postulate, some authors emphasize that it is more useful to think of personal constructs as if they were bipolar (e.g., Bannister \& Fransella, 1971). In line with this reasoning, research on personal construct theory heavily relies on several variants of the repertory grid technique (Neimeyer, 1983) which are based on the bipolarity. With a broader conceptualization of contrast relations, the rationale behind repertory grid measurement is challenged. This is especially true for mechanical applications of the repertory grid technique. Split-half sorting procedures, the simultaneous rating on two poles, and the fixed triadic comparison procedure only roughly fit a person's use of personal constructs. Important dimensions may not be mentioned in a repertory grid test simply because they do not fit the format for the elicitation of constructs (Riemann, 1987). Alternative procedures for eliciting constructs, including multiple sorting procedures (Kelly, 1955), the analysis of self-characterizations or free-response descriptions, and a careful examination of the way in which elements are related to these constructs may be useful for the psychologist who is interested in personal constructs (Bonarius, 1977). Research that aims at the representation of the elements' similarity structure in a low dimensional space (Rathod, 1981; Slater, 1977) is less affected by the elimination of the dichotomy postulate. This conclusion is suggested by the high correspondence between the elements' similarity structure computed from a repertory grid test and that provided by direct similarity ratings (Gigerenzer, 1981; Riemann, 1983).

Taken together, the present analysis demonstrates that it is more appropriate to conceptualize personal constructs as monopolar abstractions and to study contrast relations as an aspect of the constructs' organization. It seems neither necessary nor particularly useful to elicit personal constructs in a bipolar form. To explore the personal meaning of constructs, however, it is necessary to take contrasting constructs into account.

\section{REFERENCES}

Adams-Webber, J. R. (1970). Personal construct theory: Concepts and applications. London: Wiley.

Bannister, D. (1960). The nature and measurement of schizophrenic thought disorder. Joumal of Mental Science, 106, 1230-1249.

Bannister, D., \& Fransella, F. (1971). Inquiring man. Harmondsworth: Penguin.

Bonarius, H. (1977). The interaction model of communication: Through experimental research towards existential relevance. In J. K. Cole \& A. W. Landfield (Eds.), Nebraska symposium on motivation (Vol. 24). Lincoln: University of Nebraska Press.

Bonarius, H. (1984). Personal construct psychology: A reappraisal of basic theory and 
its application. In H. Bonarius, G. Van Heck, \& N. Smid (Eds.), Personality psychology in Europe: Theoretical and empirical developments. Lisse: Swets \& Zeitlinger.

Bonarius, H., Angleitner, A., \& John, O. (1983). Die psychologie der persölichen konstrukte: Eine kritische bestandsaufnahme einer persönlichkeitstheorie [Personal construct theory: A critical reconsideration]. In $\mathrm{M}$. Amelang \& $\mathrm{H}$. J. Ahrens (Eds.), Brennpunkte der persönlichkeitsforschung. Gottingen: Hogrefe.

Bonarius, J. C. J. (1965). Research in the personal construct theory of George A. Kelly: Role construct repertory test and basic theory. In B. Maher (Ed.), Progress in experimental personality research (Vol. 2). New York: Academic Press.

Bonarius, J. C. J. (1988). Personal construction needs no personal constructs: An empirical liberation from theoretical constraints. Intermational loumal of Personal Construct Psychology, 1, 273-280.

Boole, G. (1952). An investigation of the laws of thought, on which are founded the mathematical theories of logic and probabilities. La Salle, IL: Open Court Publishing $\mathrm{Co}$. (Original work published in 1854).

Buss, D. M., \& Craik, K. H. (1983). Act prediction and conceptual analysis of personality scales: Indices of act density, bipolarity, and extensity. Joumal of Personality and Social Personality, 45, 1081-1095.

Cantor, N., \& Mischel, W. (1979). Prototypes in person perception. In L. Berkowitz (Ed.), Advances in experimental social psychology. New York: Academic Press.

Cattell, R. B. (1943). The description of personality: Basic traits resolved into clusters. Journal of Abnormal and Social Psychology, 38, 476-507.

Epting, F. R., Suchman, D. I., \& Nickeson, C. J. (1971). An evaluation of elicitation procedures for personal constructs. British Joumal of Psychology, 62, 513-517.

Gigerenzer, G. (1981). Implizite persönlichkeitstheorien oder quasi-implizite persönlichkeitstheorien? [Implicit personality theories or quasi-implicit personality theories?] Zeitschrift für Sozialpsychologie, 12, 65-80.

Goldberg, L. R., \& Kilkowski, J. M. (1985). The prediction of semantic consistency in self-descriptions: Characteristics of persons and of terms that affect the consistency of responses to synonym and antonym pairs. Journal of Personality and Social Psychology, 48, 82-98.

Kay, P. (1971). Taxonomy and semantic contrast. Language, 47, 866-887.

Kelly, G. A. (1955). The psychology of personal constructs. New York: Norton.

Maimon, Z. (1978). The choice of ordinal measures of association. Quality and Quantity, $12,255-264$.

Mair, J. M. M. (1967). Some problems in repertory grid measurement. British Joumal of Psychology, 58, 261-270.

Neimeyer, R. A. (1983). The development of personal construct psychology: Some sociohistorical observations. In J. Adams-Webber \& J. C. Mancuso (Eds.), Applications of personal construct theory. New York: Academic Press.

Norman, W. T. (1963). Toward an adequate taxonomy of personality attributes: Replicated factor structure in peer nomination personality ratings. Joumal of Abnormal and Social Psychology, 66, 574-583.

Rathod, P. (1981). Methods for the analysis of repertory grid data. In H. Bonarius, $R$. Holland, \& S. Rosenberg (Eds.), Personal construct psychology: Recent advances in theory and practice. London: MacMillan.

Resnick, J., \& Landfield, A. W. (1961). The oppositional nature of dichotomous constructs. The Psychological Record, 11, 47-55.

Riemann, R. (1983). Eine untersuchung zur validität der gridtechnik [A study on the validity of the repertory grid technique]. Psychologische Beiträge, 25, 385-396.

Riemann, R. (1987). Struktur und organisation persönlicher konstrukte [Structure and organization of personal constructs]. Regensburg: Roderer Verlag. 
Rosch, E., Mervis, C. B., Gray, W. D., Johnson, D. M., \& Boyes-Braem, P. (1976). Basic objects in natural categories. Cognitive Psychology, 8, 382-439.

Slater, P. (1977). The measurement of intrapersonal space by grid technique (Vol. 2). Dimensions of intrapersonal space. London: Wiley.

Ten Kate, H. (1981). A theoretical explication of Hinkle's implication theory. In $\mathrm{H}$. Bonarius, R. Holland, \& S. Rosenberg (Eds.), Personal construct psychology: Recent adtances in theory and practice. London: MacMillan.

Wiggins, J. S. (1979). A psychological taxonomy of trait-descriptive terms: The interpersonal domain. Journal of Personality and Social Psychology, 37, 395-412.

Wijdeveld, P. (1980). De dichotome aard van de constructen nader beteken [A closer look at the dichotomy of constructs]. Nederlands Tijdschrift woor de Psychologie, 35, 371-382.

Requests for reprints should be sent to Rainer Riemann, Universität Bielefeld, Abt. Psychologie, Postfach 8640, 4800 Bielefeld, Federal Republic of Germany. 